\title{
Logic is Elementary, \\ Kindergartners are Elementary, Kindergartners are Logical
}

\section{Kevin Torres, Michele Casey and David Loker}

\author{
Penn State Erie, The Behrend College \\ Creekside Christian School
}

\begin{abstract}
From an early age, children are introduced to and provided with opportunities to use a broad range of electronic equipment. Typically after examining such equipment their first question is "What makes it work"? The purpose of this paper is to answer just such a question. Kindergartners are at a very inquisitive age, but yet little is done to reach this group primarily because concepts are thought to be beyond their understanding. This age group of students process information very basically and logically. They are at a very teachable age to present basic concepts of digital logic and in turn answer their questions of why and how.
\end{abstract}

This paper outlines digital logic experiences specifically designed for kindergarten students. The experiences are hands-on experiments with the hope that kindergartners can learn at-their-level fundamental logic concepts. Basic knowledge of digital logic through experiences is the objective. This objective will be accomplished by a variety of activities that begin with a concept, followed by student predictions and problem solving. By providing Kindergarten students with these opportunities we are equipping them with knowledge that is applicable to equipment they interact with daily. In addition, they will have had a positive experience with engineering that will hopefully ignite an interest for further learning.

\subsection{Introduction}

In 2001 an outreach project was designed and implemented to provide kindergarten students with engineering technology experiences. ${ }^{1}$ In that project kindergarten students were introduced to current, voltage, batteries, conductors and insulators. The project was not only a success with kindergarten students but also with $1^{\text {st }}$ grade students.

The authors wanted to add another module to the kindergarten engineering curriculum. The topic of digital logic was decided upon. In an ASEE 2000 paper, Cooney and Mueller designed a digital logic circuits project for second and third grade children. ${ }^{2}$ Our project would focus on the younger kindergarten students. 
The first goal of this project is that the students be introduced to new material and terms and learn to respect and use them correctly. Secondly, that the students would be confident in making predictions and then testing their theories through hands-on activities with the materials. Finally, that the students would gain an interest in electrical engineering.

\begin{tabular}{|l|l|l|}
\hline Activity - Lesson 1 & Goal - Lesson 1 & Time Frame - Lesson 1 \\
\hline Introduction & Review electric circuits & 5 minutes \\
\hline OR (Thomas train) & Recognize AND condition & 5 minutes \\
\hline OR (Electric circuit) & Apply AND condition & 10 minutes \\
\hline AND (Thomas train) & Recognize OR condition & 5 minutes \\
\hline AND (Electric circuit) & Apply OR condition & 10 minutes \\
\hline Activity Page & $\begin{array}{l}\text { Apply knowledge of } \\
\text { demonstrations }\end{array}$ & 5 minutes \\
\hline Activity - Lesson 2 & Goal - Lesson 2 & Time Frame - Lesson 2 \\
\hline Introduction And Review & $\begin{array}{l}\text { Review Lesson 1 Activities } \\
\text { Introduce Binary Code and } \\
\text { modules }\end{array}$ & 10 minutes \\
\hline Binary Code & $\begin{array}{l}\text { Label switch positions to } \\
\text { decimal equivalent }\end{array}$ & 20 minutes \\
\hline Activity page & $\begin{array}{l}\text { Apply knowledge of } \\
\text { demonstrations }\end{array}$ & 5 minutes \\
\hline
\end{tabular}

\section{Table 1. Experience Goals/Time Table}

\subsection{EET Experiences}

Three topics in digital logic circuits are introduced to the kindergarten students. They are the AND operator, the OR operator and the binary system and counting. The term binary is used in the experiences for the AND operator and OR operators so that the students become familiar with it when it comes time to do the binary system experience.

Hammond Manufacturing, Pomona Electronics, C\&K Switch Products, Bailey's Electronics, and the Penn State Erie EET program provided the funding for this project. A complete parts list is provided in Appendix A.

\subsection{AND Operator}

The AND operator is fundamental to digital logic. The AND operator is introduced with the analogy of Thomas the Tank Engine ${ }^{\mathrm{TM}}$ traveling on a track. The track is purposely missing two 
sections. The students are asked what is needed to finish the track. The answer is this section AND that section. The goal with this demonstration is knowledge and comprehension on the Bloom's taxonomy level.

Students are then given two toggle switches, an LED module, and a battery module shown in Figures 1 through 3 . The class is given this problem to work together. With the Thomas track as a model, what is the circuit so that switch \#1 AND switch \#2 must be in the ON position for the LED to turn ON. The instructors guide the students into connecting the switches in a series fashion and related the circuit back to the Thomas track, as shown in Figure 4. The circuit for the AND configuration is shown in Figure 5. The goal with this experience is application and analysis on the Bloom's taxonomy level.

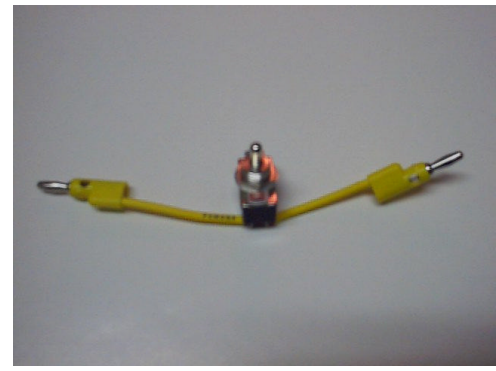

Figure 1 Toggle Switch

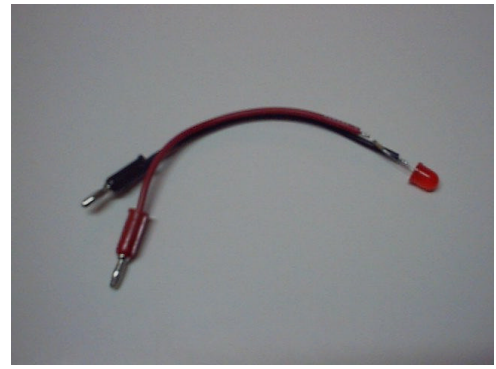

Figure 2 LED Module

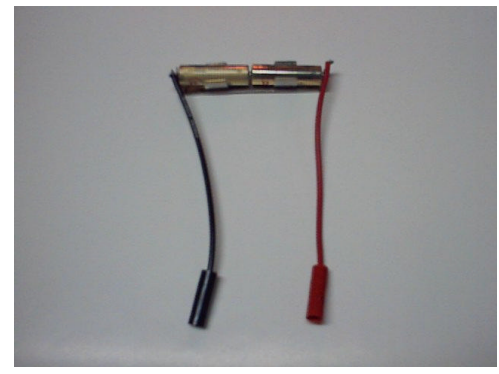

Figure 3 Battery Module

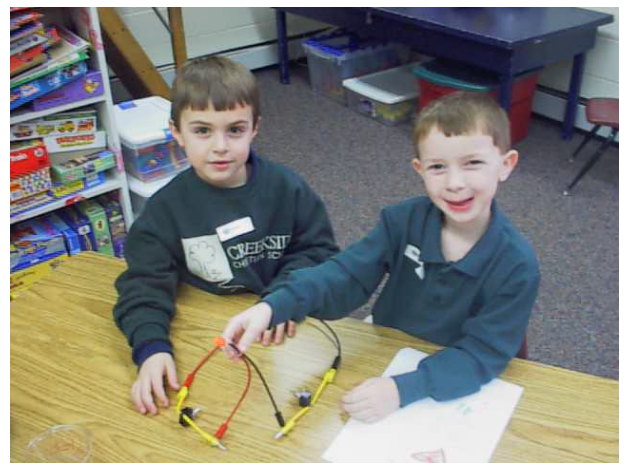

Figure 4 AND Experience

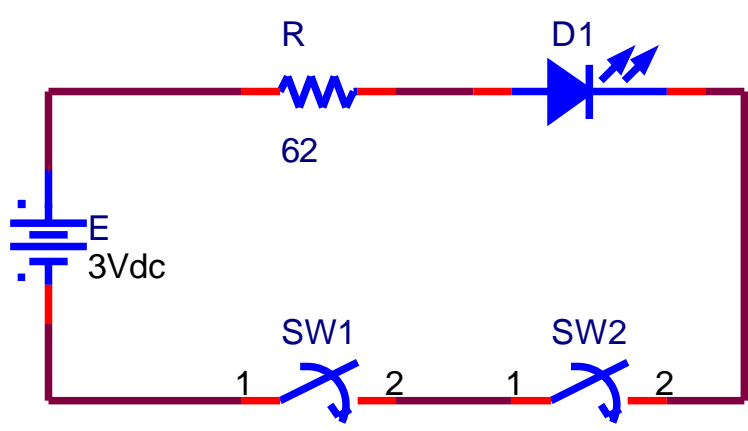

Figure 5 AND Circuit

\subsection{OR Operator}

The OR operator is also fundamental to digital logic. The OR operator is also very common in every day decision making. Where to go, what to do, ... ${ }^{3}$

The OR operator is introduced with the analogy of Thomas the Tank Engine ${ }^{\mathrm{TM}}$ needing to make a decision between two tracks (Figure 6). The "Engine Shed Switch Track" is used to demonstrate this concept. The students are asked how Thomas can get from one place to another. The answer is this way OR that way. 


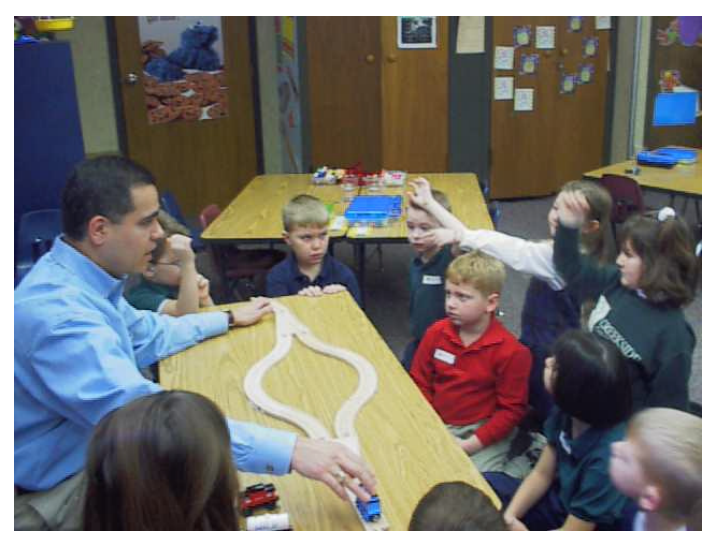

Figure 6 OR Demonstration

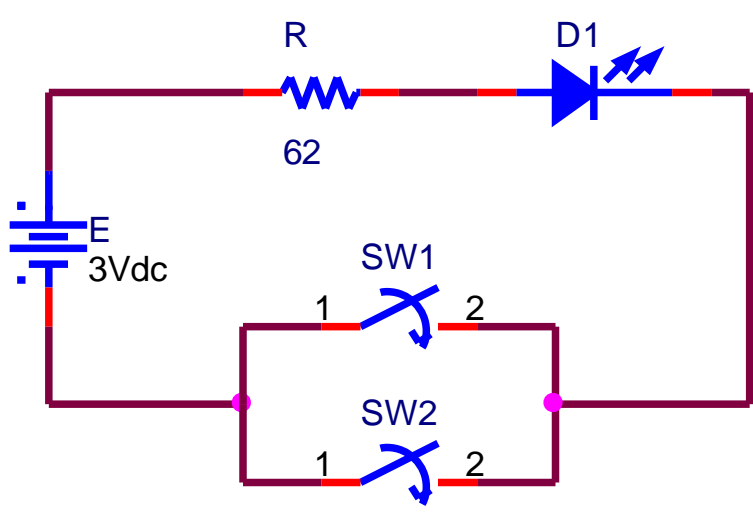

Figure 7 OR Circuit

Using the components from the AND experience students are asked to build a circuit so that switch \#1 OR switch \#2 can be in the ON position for the LED to turn ON. The students work in this experience individually. The circuit for the OR configuration is shown in Figure 7 . The goal with this experience is application, analysis synthesis on the Bloom's taxonomy level.

\subsection{Binary system and code}

Now that the students have seen how one switch can turn an LED on(1) or off(0) the concept of a binary code is introduced. Kindergarten students are beginning to learn the decimal system and counting in the decimal system. However, the decimal system does not lend itself to the application of digital logic circuits. The students are told that all the numbers in the decimal system can be represented in a binary system of 0 s and $1 \mathrm{~s}$. And that the binary system is used in $\mathrm{CD}$, computers, clock radios, calculators, ... The students are given a binary counting module that consists of four switches and an LED display as shown in Figure 8. The schematic is shown in Figure 9. The are also given an activity sheet of the binary counting sequence along with the decimal equivalent. Through experimentation they are asked to complete the table as shown in Figures 10 and 11.

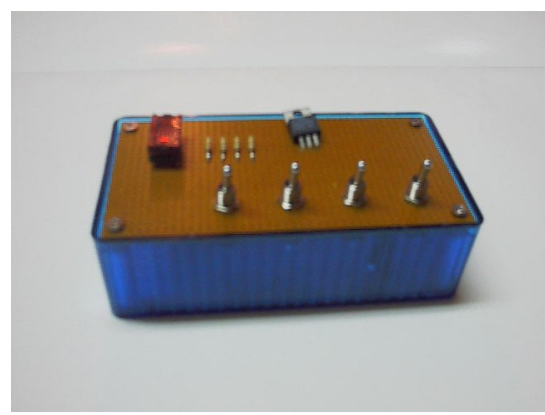

Figure 8 Binary Counting Module 

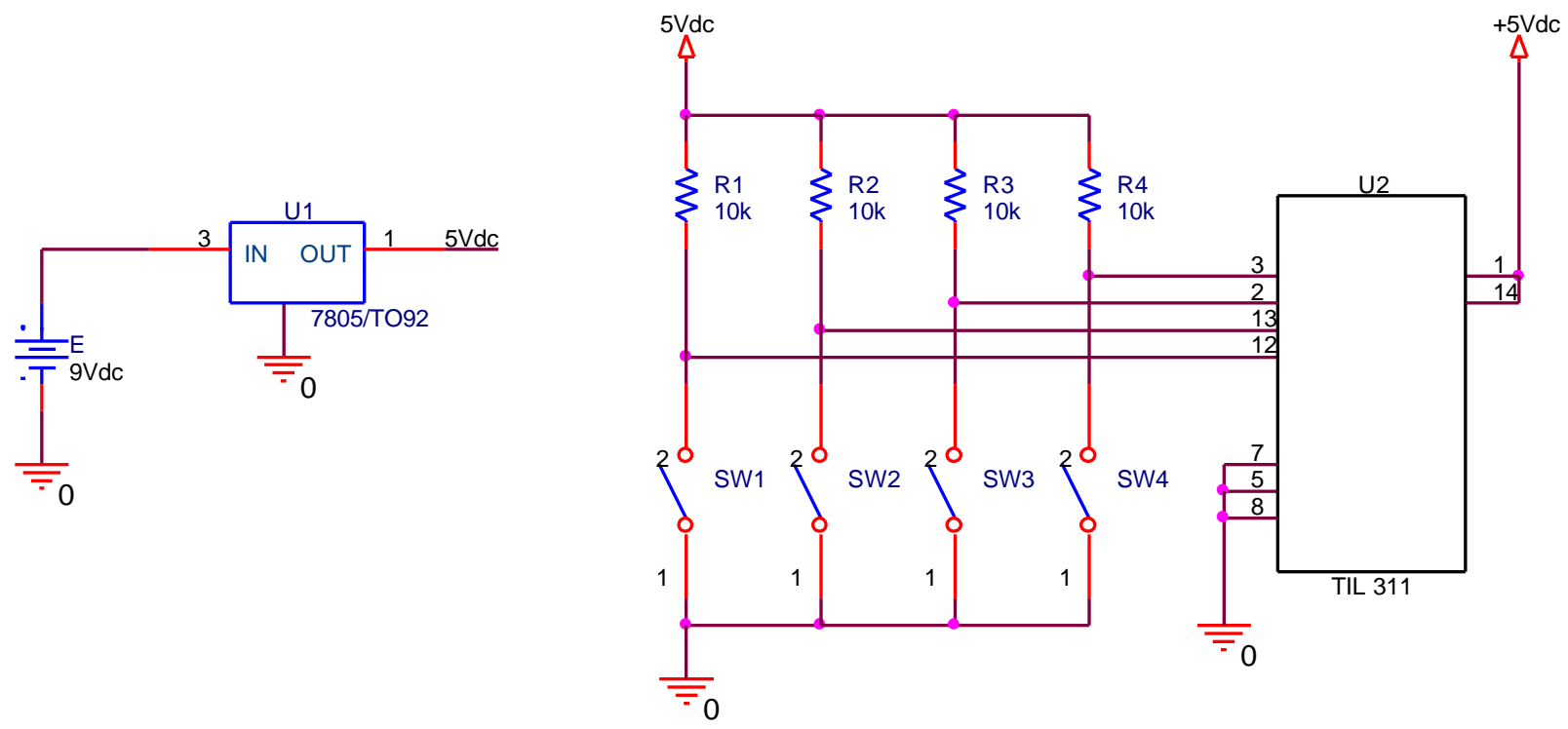

Figure 9 Binary Counting Schematic

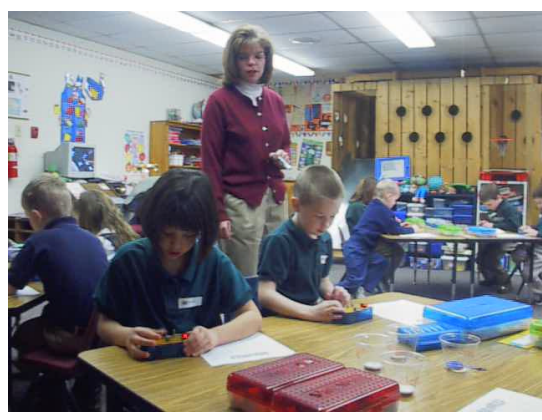

Figure 10 Binary Experience

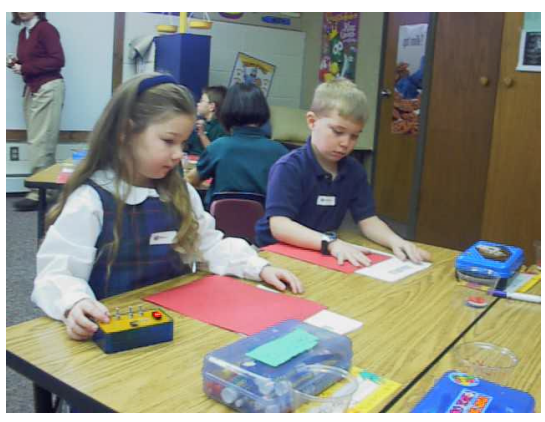

Figure 11 Binary Experience

\subsection{Program Assessment}

Due to the fact that the group consists of kindergarten students, they will be assessed primarily on a performance basis. Students will demonstrate their knowledge and understanding of the information presented through their participation and performance in the above mentioned activities. In addition to the performance assessment, students will also be evaluated using activity pages where they will categorize objects into two classes depending upon the criteria.

\subsection{Assessment For AND/OR Operator}

Students will demonstrate an understanding of the AND/OR operators by identifying objects that are dependent upon one another to operate or objects that provide you with a choice of how to use it. Students will then complete an activity page, shown in Appendix B, that illustrates objects found in their home that need to be either used together to work correctly or independently of each other. 


\subsection{Assessment For Binary System and Code}

Through the activities, students will demonstrate an understanding of the Binary Code System by placing the 4 switches on the module in correct sequence to display a specific decimal number. The students will then be given a portion of a code and a decimal number. Through experimentation, the students will solve for the missing code and display the designated decimal number. Students will then complete an activity page, shown in Appendix C, and identify objects in their home that use binary code to operate.

\subsection{Conclusion}

The class was very enthusiastic about the project and actively participated in the demonstrations and hands-on experiments. Using the Thomas track to demonstrate AND/OR provided the students with a tangible way to understand the principles at their learning level. The theory of logic is very abstract to most adults, but through these activities, the students were able to concretely experience the principle, gain an understanding of them, and lay a foundation to build upon. The students thoroughly enjoyed using the binary code modules and felt very successful during the experimentation and problem solving process. The goals set for this project were not only met, but exceeded the expectations.

\subsection{Acknowledgements}

The authors would like to thank Hammond Manufacturing, Jim La Croix with Pomona Electronics, Natalie Rowe with C\&K Switch Products, Matt Wagner with Bailey's Electronics, and the Penn State Erie EET program. These individuals and their corporations donated the supplies for this engineering kindergarten project. The project could not have been completed without their support.

\footnotetext{
${ }^{1}$ Torres, Kevin, Casey, Michele, "Electrical Engineering Technology Experiences for Kindergarten Students", Proceedings 2001 ASEE Annual Conference.

${ }^{2}$ Cooney, Elaine, Mueller, Arlene, "Logic to Electronics: A Teaching Unit for Elementary Students", Proceedings 2000 ASEE Annual Conference.

${ }^{3}$ Houghton, Janaye, Houghton, Robert, Circuit Sense for Elementary Teachers and Students, Teachers Idea Press, pp 251994.
} 


\section{KEVIN TORRES}

Kevin M. Torres is a lecturer in engineering and received the B.E.E. degree (Cum Laude) from Auburn University in 1990, and the M.S.E.E. degree from Georgia Institute of Technology in 1996. In 1990 he joined Georgia Tech

Research Institute (GTRI) as a research engineer. In 1998, he joined the faculty at Pennsylvania State University, Erie, in the Electrical Engineering Technology Program. Since 1998 he has been teaching courses in C++, Intermediate Microcontrollers and Advanced Microcontrollers. He is a member of IEEE, IMAPS, and ASEE.

\section{MICHELE CASEY}

Michele Casey is a kindergarten teacher at Creekside Christian School in North East, Pennsylvania. She received her B.S. degree in Elementary Education from Edinboro University of Pennsylvania in 1995.

\section{DAVID LOKER}

David R. Loker is an assistant professor of engineering and received the B.E.E. degree from Gannon University in 1984, and the M.S.E.E. degree from Syracuse University in 1986. In 1984, he joined General Electric (GE) Company, AESD, as a design engineer. While at GE, Mr. Loker was primarily involved in the design and development of military communication systems. In 1988, he joined the faculty at Pennsylvania State University, Erie, in the Electrical Engineering Technology Program. Mr. Loker's research interests include PC-based control systems, communication systems, and instrumentation systems. 
Appendix A

\section{Parts List}




\begin{tabular}{|c|c|c|c|}
\hline QTY & https://www.bobstrains.com/ & & \\
\hline 1 & Engine Shed Switch Track & $\$ 9.60$ & $\$ 9.60$ \\
\hline 1 & 6 1/2 Curved Track - 4 pcs. & $\$ 9.60$ & $\$ 9.60$ \\
\hline QTY & Hammond Manufacturing & & \\
\hline 25 & 1591CTBU Blue enclosure & $\$ 5.27$ & $\$ 131.75$ \\
\hline QTY & RadioShack & & \\
\hline 10 & 276-1394 perfboards & $\$ 2.49$ & $\$ 24.90$ \\
\hline QTY & Jameco & & \\
\hline 26 & 76241 full size tobble switch & $\$ 0.99$ & $\$ 25.74$ \\
\hline 13 & 112799 volt battery snap & $\$ 0.17$ & $\$ 2.21$ \\
\hline 13 & 1057939 volt battery holder clip & $\$ 0.15$ & $\$ 1.95$ \\
\hline 13 & 62050 Wire wrap socket(14 pin) & $\$ 0.79$ & $\$ 10.27$ \\
\hline 13 & 51262 TO-220 5 V Regulator & $\$ 0.25$ & $\$ 3.25$ \\
\hline QTY & Jameco & & \\
\hline 12 & 76241 full size tobble switch & $\$ 0.99$ & $\$ 11.88$ \\
\hline QTY & Pomona Electronics & & \\
\hline 15 & 4702-12-0 Black cable & $\$ 5.15$ & $\$ 77.25$ \\
\hline 15 & 4702-12-2 Red cable & $\$ 5.15$ & $\$ 77.25$ \\
\hline 10 & B-4-4 Yellow cable & $\$ 3.85$ & $\$ 38.50$ \\
\hline QTY & C\&K & & \\
\hline 50 & $7101 S Y Z Q E 7000$ series toggle switch & $\$ 3.00$ & $\$ 150.00$ \\
\hline 50 & 700201264 Nickel plateed hex nut & $\$ 0.22$ & $\$ 11.00$ \\
\hline QTY & Bailey's Electronics & & \\
\hline 20 & SSL-LX100133ID leds & $\$ 0.60$ & $\$ 12.00$ \\
\hline
\end{tabular}


Appendix B

Activity Sheet 
Directions: Circle in blue the pictures that need to be used together. Circle in red the pictures that you can use one or the other.
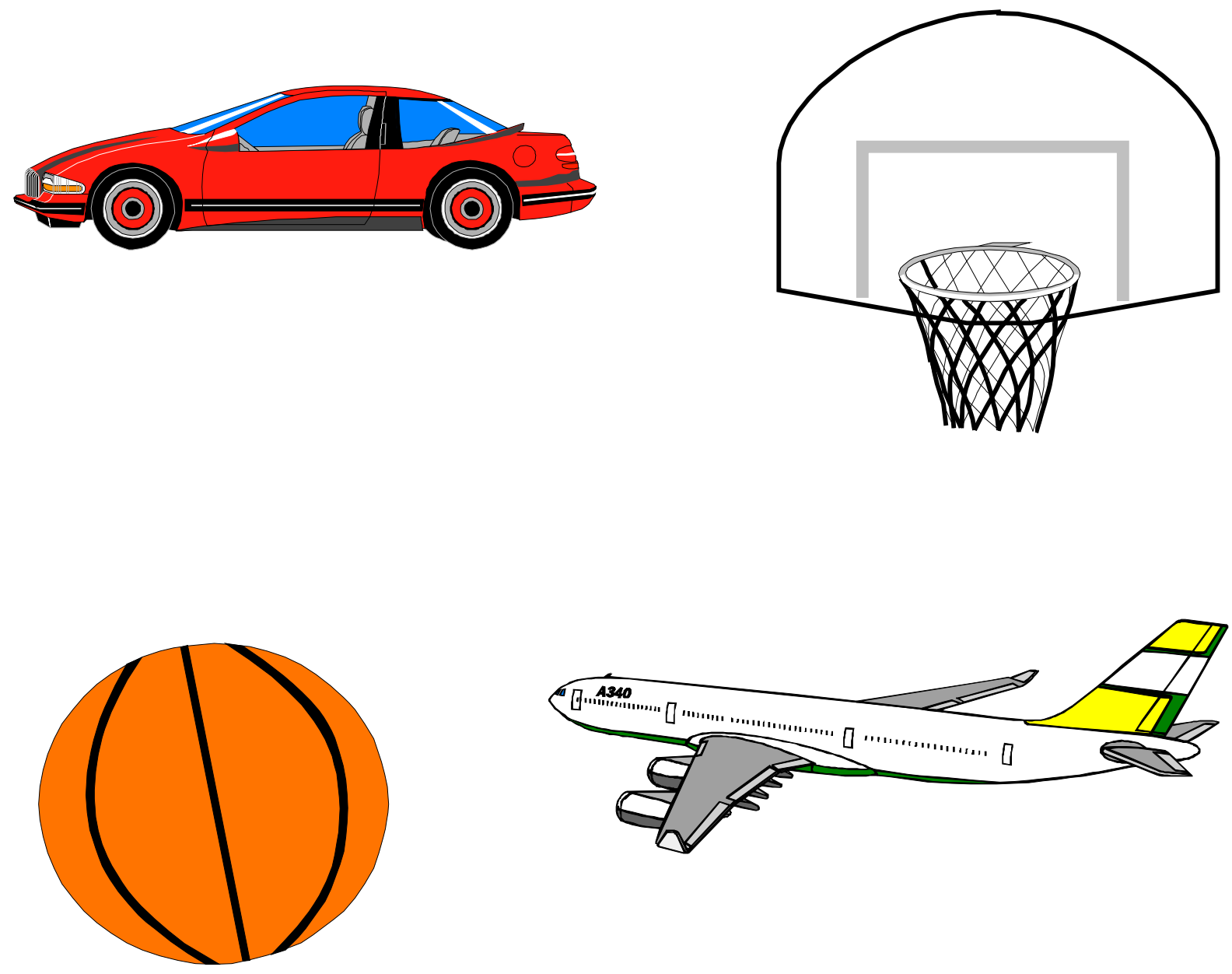


\section{Appendix C}

\section{Activity Sheet}


Name

Directions: Circle the pictures of the items that use binary code.
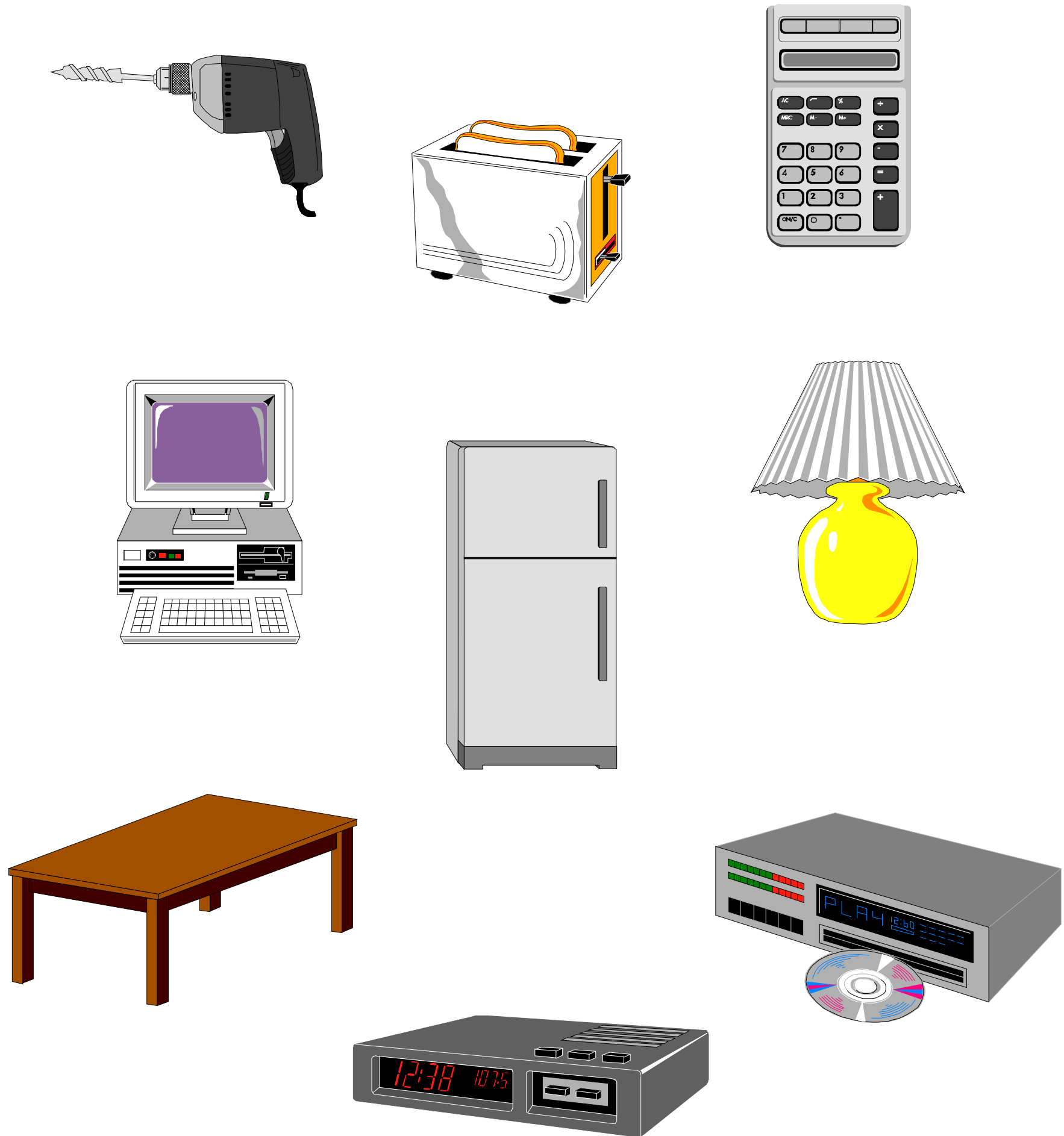

Proceedings of the 2002 American Society for Engineering Education Annual Conference \& Exposition Copyright ( 2002, American Society for Engineering Education 